\title{
FUNDAMENTOS E PRÁTICAS DA EDUCAÇÃO PROFISSIONAL E TECNOLÓGICA: REFLEXÕES E PROPOSTAS DE ESTUDO A PARTIR DE UM MESTRADO PROFISSIONAL
}

\author{
Emerson Freire (CEETEPS-SP)* \\ Sueli Soares dos Santos Batista (CEETEPS-SP)**
}

\begin{abstract}
RESUMO
A expansão dos cursos em Educação Profissional e Tecnológica (EPT) nos últimos anos tem trazido desafios significativos nessa área, seja na rede pública ou privada. Dentre eles está o estabelecimento de programas de pós-graduação que permitam formar docentes, gestores e pesquisadores voltados para a realidade da EPT, conhecendo seus limites e possibilidades. Mais ainda, trata-se também de criar perspectivas de leitura, reflexões e estudos nessa modalidade de ensino. A partir da experiência docente e em pesquisa em EPT dentro do Programa de Mestrado Profissional em Gestão e Desenvolvimento da Educação Profissional, numa instituição pública paulista que atua na formação técnica e tecnológica desde 1969, os autores propõem neste artigo uma dessas possíveis perspectivas, considerando algumas trilhas básicas de investigação levantadas no contexto da arquitetura curricular de uma disciplina intitulada Fundamentos e Práticas da EPT. Parte-se da hipótese de que é necessário conhecer os fundamentos epistemológicos das relações entre educação e trabalho; problematizar o papel da EPT no atual contexto do desenvolvimento tecnocientífico, compreender as interfaces entre educação, sociedade e tecnologia a partir dos estudos da historiografia da Educação Profissional e Tecnológica, identificando as mudanças e permanências na sua fundamentação legal.

Palavras-chave: Mestrado profissional. Fundamentos da educação profissional e tecnológica. Gestão e desenvolvimento da educação profissional e tecnológica.
\end{abstract}

\section{ABSTRACT \\ FUNDAMENTALS AND PRACTICES OF PROFESSIONAL AND TECHNOLOGICAL EDUCATION: REFLECTIONS AND STUDY PROPOSALS FROM A PROFESSIONAL MASTER}

The expansion of courses in Vocational and Technological Education (VTE) in recent years has brought significant challenges, whether in the public or private system.

\footnotetext{
* Doutor em Sociologia pela Universidade Estadual de Campinas (UNICAMP). Doutor em Filosofia pela Universidade de Paris 1 - Panthéon Sorbonne. Docente do Programa de Mestrado Profissional em Gestão e Desenvolvimento da Educação Profissional do Centro Estadual de Educação Tecnológica Paula Souza (CEETEPS-SP). Coordenador do Núcleo de Estudos de Tecnologia e Sociedade da Faculdade de Tecnologia do Estado de São Paulo (NETS/FATEC-Jundiaí). E-mail: freire. emerson@uol.com.br

** Doutora em Psicologia da Aprendizagem pela Universidade de São Paulo (USP). Docente do Programa de Mestrado Profissional em Gestão e Desenvolvimento da Educação Profissional do Centro Estadual de Educação Tecnológica Paula Souza (CEETEPS-SP). Coordenador do Núcleo de Estudos de Tecnologia e Sociedade da Faculdade de Tecnologia do Estado de São Paulo (NETS/FATEC Jundiaí). E-mail: suelissbatista@uol.com.br
} 
Among them is the establishment of postgraduate programs to provide teachers, managers and researchers to face the reality of VTE, acknowledging its limits and possibilities. Moreover, it is also about creating perspectives for reading, reflections and studies in this type of education. From teaching experience and research in VTE within the Professional Master's Program in Management and Development of Vocational Education in São Paulo public institution engaged in technical and technological education since 1969, the authors propose in this article one of these possible perspectives, considering some basic tracks research raised in the context of curriculum architecture of a course entitled "Fundamentals and Practices on VTE". The hypothesis is that is necessary to know epistemological foundations of the relationship between education and labor; problematize the VTE role concerning the present techno-scientific development context, trying to understand the interfaces among education, society and technology from a historiographical researches on Vocational and Technological Education, identifying the changes and continuities in legal basis. Keywords: Professional masters. Management and development of vocational education. Vocational and technological education.

\section{RESUMEN}

\section{FUNDAMENTOS Y PRÁCTICAS DE LA EDUCACIÓN PROFESIONAL Y TECNOLÓGICA: REFLEXIONES Y PROPUESTAS DE ESTUDIO A PARTIR DE UN MASTER PROFESIONAL}

La expansión de los cursos en Educación Profesional y Tecnologíca (EPT) en los últimos años ha traído consigo importantes desafíos en esta área, sea en la red pública o privada. Entre ellos se encuentra el establecimiento de programas de posgrado para capacitar a los profesores, gestores e investigadores involucrados con la realidad de la EPT, conociendo sus límites y posibilidades. Por otra parte, también es necesario crear perspectivas de lectura, reflexiones y estudios en este tipo de educación. Desde la experiencia docente y en la investigación acerca de la EPT en el Programa de Maestría Profesional en Gestión y Desarrollo de la Educación Profesional en una institución pública en Sao Paulo que ha realizando acciones de formación técnica y tecnológica desde 1969, los autores proponen en este artículo una de estas perspectivas posibles, teniendo en cuenta algunas pistas básicas de investigación que en el contexto de la arquitectura curricular de una materia del curso titulada "Fundamentos y Prácticas de la EPT". Se inicia con la hipótesis de que es necesario conocer los fundamentos epistemológicos de la relación entre la educación y el trabajo; problematizar el papel de la EPT en el contexto actual de desarrollo tecnocientífico, comprender las interfaces entre la educación, la sociedad y la tecnología en vista de la historiografía de los estudios de educación profesional y tecnológica, la identificación de los cambios y continuidades en su fundamentaciòn legal.

Palabras claves: Maestría profesional. Fundamentos profesionales de educación y tecnología. Gestión y desarrollo de la educación profesional y tecnológica.

\section{Introdução}

Os autores deste artigo, ao desenvolverem atividades de ensino e pesquisa quanto aos fundamentos e práticas da Educação Profissional e Tecnológica (EPT), propõem uma perspectiva de leitura, refle- xão e estudos nessa modalidade de ensino que estejam para além da fidelização a autores e correntes teóricas específicas, tendo como centro a ideia de uma educação para a emancipação num contexto 
amplo de transformações sociais e de contradições do mundo do trabalho. Na apresentação e discussão dessa perspectiva, os autores se debruçam sobre a sua vinculação ao Programa de Mestrado Profissional em Gestão e Desenvolvimento da Educação Profissional, numa instituição pública paulista que atua na formação técnica e tecnológica desde 1969. Esse programa anuncia como compromisso a busca de uma efetiva interferência na realidade da EPT por meio do processo de formação de professores e gestores e do desenvolvimento de práticas inovadoras no processo de ensino-aprendizagem.

A Coordenação de Aperfeiçoamento de Pessoal de Nível Superior (Capes), em documento informativo de 1999, considerou que com a oferta do Mestrado Profissional, na época designado "profissionalizante", ampliava-se a interface com os setores não acadêmicos da sociedade brasileira voltando-se também para a formação de mestres para o exercício de profissões outras que não as de docente pesquisador (COORDENAÇÃO DE APERFEIÇOAMENTO DE PESSOAL DE NÍVEL SUPERIOR, 1999; SILVEIRA; SOUZA PINTO, 2005). Passados esses anos do início da implementação dos mestrados profissionais, os estudos e debates em torno da sua natureza, da sua especificidade e das suas formas de financiamento, continuam sendo cruciais dada a complexidade do cenário tecnocientífico e a expansão das redes de EPT, que têm ocorrido de forma verticalizada, abarcando do ensino básico à pós-graduação.

A existência dos programas de mestrado profissional tem sido comumente atribuída ao atendimento de demandas crescentes do setor produtivo e da consolidação de um ambiente de ensino articulado à extensão e às atividades de pesquisa, desenvolvimento e inovação (QUELHAS; FARIA FILHO; FRANÇA, 2005). Entretanto, esta expectativa tem ganhado discussões mais ampliadas à medida que a necessidade da pesquisa científica e tecnológica tem alcançando outros níveis e situações de profissionalização que não podem ser entendidos simplesmente como algo oposto à formação acadêmica.

Quais são os desafios na concepção e implementação de um programa de mestrado profissional que, dada a situação de expansão vertiginosa das escolas voltadas para a EPT a partir dos anos
2000, exige a formação de quadros para atuar nas diferentes redes, públicas e privadas, em diferentes esferas da Federação e também alcançando a realidade das empresas? Formar docentes para a EPT é algo a se consolidar num contexto também de formação de gestores que possam implementar cursos, programas, instituições e políticas de EPT. Contudo, não só isso. Articulada a esta formação para a docência e para a gestão está a formação de pesquisadores que possam analisar todo esse processo, compreendendo seus pressupostos, seus limites e suas possibilidades.

Parte-se da hipótese de que é necessário, nessa tarefa, conhecer os fundamentos epistemológicos das relações entre educação e trabalho; problematizar o papel da formação profissional no atual contexto do desenvolvimento tecnocientífico; compreender as interfaces entre educação, sociedade e tecnologia a partir dos estudos da historiografia da EPT, identificando as mudanças e permanências na sua fundamentação legal.

Não se trata, portanto, de pontuar aqui aspectos e desafios da arquitetura curricular dos ainda poucos programas de mestrado profissional em educação profissional existentes, mas de defender e contribuir para uma verticalização da fundamentação teórica em relação aos estudos que procuram associar profissionalização aos desafios atuais relacionados à tecnologia, à sociedade e ao trabalho nas relações dialéticas que se estabelecem entre essas instâncias interdependentes.

Propõe-se, assim, como matrizes condutoras de um trabalho de ensino e pesquisa na pós-graduação com enfoque em EPT, quatro trilhas investigativas que são apresentadas de forma separada apenas para fins didáticos. Essas trilhas são: a) os estudos sobre a centralidade do trabalho nas ideias e práticas educativas; b) os estudos sobre os conceitos de tecnologia e as noções a ela atribuídas nas práticas socioculturais, numa dimensão que considere as reflexões sobre a tecnocultura e o atual desenvolvimento tecnocientífico; c) os estudos sobre a história da EPT enquanto espaço de conflitos e contradições em torno das diferentes concepções de educação e de trabalho, bem como das relações estabelecidas entre essas dimensões; e d) os estudos sobre a fundamentação legal subjacente aos cenários da EPT que têm legitimado diferentes políticas de governo 
e políticas de Estado em diálogo (ou não) com as reivindicações de diferentes segmentos sociais.

Essas trilhas inicialmente elencadas são, em grande parte, o conteúdo programático de uma ação institucional e acadêmica que está sendo construída junto a pós-graduandos que têm a EPT como objeto de pesquisa, mas também como ambiente de trabalho e de formação permanente. Esta ação, aqui parcialmente apresentada e discutida, dá-se no contexto específico de uma disciplina intitulada Fundamentos e Práticas da EPT, articulando-se também às atividades de pesquisa de orientadores e orientandos que concebem e desenvolvem projetos de pesquisa nesta direção.

Nos limites deste artigo, são apresentados os esforços de uma abordagem teórica que se direciona epistemologicamente ao mundo do trabalho e aos conceitos em torno do trabalho, de sua centralidade, de suas transformações ao longo dos anos, das noções de profissão, de empregabilidade, entre outras, vistas não isoladamente, mas na interface com o desenvolvimento tecnológico.

Ao observar o histórico da EPT, é comum a necessidade de se revisitar os conceitos de trabalho, profissão e emprego em sua relação com a escolarização, como o faz Manfredi (2002). Isso porque no bojo das transformações tecnológicas, principalmente no desenvolvimento do capitalismo industrial, e agora o informacional, o tipo e a qualidade da formação educacional e suas implicações estão sempre colocados em pauta, e em xeque.

Assim é que neste estudo são apresentados, inicialmente, aspectos importantes desta trajetória da formação profissional no Brasil, que se constituiu numa tentativa de dar soluções para as demandas de inserção social dos estudantes, sendo essa tentativa reiteradamente utilizada para legitimar práticas, projetos, programas e políticas para a EPT nem sempre exitosos, nem sempre concebidos de maneira integrada.

$\mathrm{Na}$ sequência do estudo é apresentada a problematização das mais recentes abordagens legitimadoras das teorias e práticas da EPT construídas por meio das noções de empregabilidade e de competências, comumente não confrontadas com as teorias e práticas relativas ao trabalho e a tecnologia na sua relação com a cultura e com a educação.
Na última seção é enfatizada a relevância do resgate das experiências de trabalho na formação dos trabalhadores, o aspecto histórico-social das lutas pela qualidade de vida no trabalho e a precarização do trabalho como parte do que se convenciona chamar fundamentos da educação profissional e tecnológica.

Considerando o contexto do Mestrado Profissional em que os autores atuam, programa este autorizado pela Capes em abril de 2014, numa instituição que tem como centro de sua estruturação e trajetória a formação para o mundo do trabalho, o artigo enfatiza o esforço de reflexão permanente quanto à concepção e à efetivação de uma pós-graduação nessa área, procurando verticalizar os estudos e discussões quanto à fundamentação epistemológica, histórica e sociocultural na compreensão do papel estratégico da EPT.

\section{A formação profissional no Brasil: em busca da inserção dos jovens no mundo do trabalho}

Se por séculos a formação técnica se dava nas oficinas, na relação de aprendizagem muitas vezes informal entre mestre e aprendiz, em que aspectos ético-culturais faziam parte da aquisição do conhecimento, superando a simples transmissão de habilidades técnico-profissionais, nas sociedades industriais os laços entre educação formal e produtividade em larga escala passaram a ser mais estreitos e, muitas vezes, tais aspectos éticos-culturais se transformaram ou mesmo se diluíram, tendendo à extinção (BRYAN, 2008).

A formação para o trabalho seguiu por muitos séculos, como lembra Manfredi (2002), a própria dinâmica social e comunitária. As atividades da comunidade e aquelas para o trabalho formavam um conjunto cultural específico e inseparável, sendo que essas últimas, do trabalho via aprendizado informal, muitas vezes constituíam "a única escola de que homens e mulheres e jovens adultos, das classes populares dispunham" (MANFREDI, 2002, p. 53), ou seja, uma espécie de aprendizado cultural. Todavia, a autora acredita que essa aprendizagem informal, englobando o domínio dos métodos, técnicas e rotina das tarefas, persiste ainda na atualidade, mas por vezes encontra-se "invisível 
nos espaços de trabalho", distinguindo o processo educativo do ambiente do trabalho daquele vivenciado dentro dos muros escolares.

Compreende-se que os aspectos socioculturais, ou ético-culturais, como denomina e enfatiza a autora, não somente configuram uma formação para o trabalho não restrito aos elementos técnico-profissionais, como também indicam uma pista para o distanciamento entre o que é ensinado na escola e o que ocorre no "mundo concreto do trabalho", como diz Manfredi (2002). Acrescenta-se aqui também uma pista para o descompasso entre ensino e uma produção tecnológica emancipatória em primeira e em última instância que direcione suas potencialidades para resoluções de problemas para um maior número de pessoas.

Percebe-se, para usar as palavras da própria autora, que em realidade:

A educação no e para o trabalho é um processo complexo de socialização e aculturação de jovens e adultos nos espaços de trabalho, entrecruzando-se com as aprendizagens realizadas em outros espaços socioculturais: bairro, escola, família, sindicato, partido, movimentos sociais e políticos, além de diferentes momentos da vida de cada sujeito-trabalhador. Trata-se de processos de aprendizagem multifacetados, mediados por relações de historicidade entre sujeitos, contextos e tempos (MANFREDI, 2002, p. 54 , grifo do autor).

Há que se realizar, portanto, permanentemente, estudos e pesquisas em torno da realidade concreta dos estudantes, realidade esta permeada pelo mundo do trabalho. Ou seja, como afirma Frigotto (2009), não se trata de uma discussão semântica do que seria trabalho, abstraída das relações sociais, mas que considere a complexidade dos espaços e processos de aprendizagem, socialização e aculturação destes sujeitos-trabalhadores.

Nesse contexto de socialização e aculturação nos espaços de trabalhos, como diz Manfredi (2002), o segmento social sobre o qual as políticas de educação profissional têm mais se debruçado é a juventude. Disso decorre a necessidade de verificar se e como os programas e cursos de EPT propostos consideram a necessidade de articulação entre formação profissional, trabalho, vida social e cultural do jovem.
Silva, Pelissari e Steimbach (2013, p. 415), pesquisando sobre a evasão escolar em cursos técnicos profissionalizantes de nível médio no Paraná, na perspectiva de uma busca por uma compreensão maior do que sejam as "juventudes brasileiras", chamam atenção para:

[...] a necessidade de se questionar qual é a expansão do ensino técnico que está em jogo no Brasil, quando, na verdade, o que é levado a cabo pelo poder público é uma expansão que não se propõe a alterar a essência estrutural da educação técnica, mas, sob o discurso da democratização, simplesmente ampliar o acesso a esse nível de ensino em sintonia com as demandas do mercado e do desenvolvimento, sem uma problematização mais profunda acerca de questões que são centrais para o processo de educação formal, como o currículo, as visões e os anseios dos alunos, a cultura escolar e a gestão da escola pública. Basta lembrar, por exemplo, que estamos falando de processos educativos regulamentados por um currículo que procura integrar educação propedêutica e ensino profissional e que não dá conta de apresentar a tecnologia em sua construção histórica mediada por relações sociais.

Essa expansão que se pretende como democratização do ensino, principalmente centrada na juventude, parece estar mais afeita ao aumento de indicadores de cunho econômico para sanar demandas de mercado, muitas vezes deixando aspectos importantes para a formação dos alunos, inclusive seus próprios anseios, em segundo plano.

Juventude é algo que se configura para além de uma faixa etária, num processo em que há a interface e a articulação de diversos elementos que constituem a autonomia material e afetiva dos sujeitos. Na obra organizada por Abramo e Branco (2005), alguns desses elementos são apresentados, como os relacionamentos afetivo-sexuais, a conjugalidade, a reprodução, a participação social, as práticas e espaços de cultura e entretenimento, a escolarização e a profissionalização.

Segundo dados da Organização Internacional do Trabalho (OIT), entre 2005 e 2011, em um contexto de crescimento econômico, o desemprego de jovens entre 15 e 24 anos diminuiu de 16,4\% para 13,9\%, mas essa taxa continua sendo o dobro da taxa global e três vezes maior do que a taxa entre adultos. Cerca de seis em cada 10 jovens que conseguem um emprego estão em condições informais. $\mathrm{O}$ do- 
cumento mostra que, no Brasil, a probabilidade de jovens ficarem desempregados (20\%) é superior ao resto da população (7\%) (ALCÂNTARA; COSTA; 2014; LEITÃO, 2014).

Apesar das defasagens e dívidas sociais, e também por conta delas, a juventude brasileira é uma juventude trabalhadora. Segundos dados da pesquisa Agenda Juventude Brasil (SNJ, 2014), a grande maioria dos jovens, $65 \%$, tem sua primeira inserção no mundo do trabalho mesmo antes de completar 18 anos de idade. Na zona rural, $47 \%$ dos jovens entram no mundo do trabalho antes dos 15 anos.

Sabendo que a juventude brasileira é uma juventude trabalhadora, é importante considerar que cerca de $70 \%$ está empregada ou procurando emprego, tentando conciliar educação e trabalho. Por isso, é possível concordar com Marques (2014) quando afirma que os eventos que mais caracterizam a juventude, no Brasil de modo geral, são a escola e/ou a participação no mercado de trabalho.

O que tem sido predominante é a necessidade dos cursos técnicos e tecnológicos darem conta da inovação tecnológica a qualquer custo, seguindo a lógica das competências, do aumento da eficiência e da performance produtiva, responsabilidade que recai sobre os ombros desses jovens. Se por um lado é possível e necessário verificar a viabilidade e a efetividade destas relações entre trabalho e educação, também é importante dedicar estudo às suas lacunas, como tem evidenciado o diagnóstico recentemente realizado pelo IBGE quanto à geração "nem-nem": ou seja, a parcela significativa de brasileiros entre 18 e 25 anos que nem trabalham nem estudam (INSTITUTO BRASILEIRO DE GEOGRAFIA E ESTATÍSTICA, 2015). Há a preocupação destes jovens não desenvolverem rapidamente as competências necessárias para sua inserção no chamado setor produtivo.

Compreender as "juventudes brasileiras" para, a partir desta compreensão, criar caminhos de acesso à escolarização e à profissionalização tem ficado em segundo plano na medida em que a maior parte dos esforços educativos acabam sendo para adaptar estas possíveis juventudes à uma realidade unívoca de tecnologia e de desenvolvimento tecnocientífico, pautada pelos discursos da inovação e do empreendedorismo como suficientes em si mesmos, sem problematiza-los de modo mais aprofundado, uma vez que aparecem quase como marketing oficial para dar conta desse processo.

A lógica é da formação permanente, da aquisição constante de competências, da diminuição da pesquisa, que se reflete no tipo de formação que é oferecida a esses jovens, com os seus mais variados efeitos, desde os socioeconômicos aos psicossociais. O filósofo francês Gilles Deleuze (1992, p. 226, grifo do autor), ao perceber a introdução da "empresa" em todos os níveis de escolaridade, observava que "[...] muitos jovens pedem estranhamente para serem 'motivados', e solicitam novos estágios e formação permanentes; cabe a eles descobrir a que estão sendo levados a servir; assim como seus antecessores descobriram, não sem dor, a finalidade das disciplinas."

A partir dos anos de 1990, currículos de nível básico, médio e universitários começam a ser elaborados por competências. Na institucionalização da lógica das competências na educação brasileira, o Estado tem sido responsável pela criação e implementação de leis, decretos, parâmetros e diretrizes nesse sentido. A educação profissional e tecnológica, nessa "era das diretrizes" em obediência a acordos internacionais, não escapa à tendência, muito pelo contrário. Ela se depara, pelo menos na trajetória brasileira, com sua própria constituição problemática, com suas idas e vindas em razão do leme dirigido pelo sistema produtivo, carente de uma conceituação mais elaborada e continuada que leve em consideração a inter-relação e a complexidade das noções de ciência, técnica e tecnologia na sua relação com o mundo do trabalho (BATISTA; FREIRE, 2015; CASTIONI, 2010; CIAVATTA; RAMOS, 2012; MACHADO, 2008, 2010).

\section{Tecnologia, desempenho e formação profissional: a noção de competências}

A noção de uma formação tecnológica para o mercado, calcada apenas em índices de empregabilidade, ainda que eles sejam relevantes, acaba por obscurecer sua função social e estratégica. A própria conceituação de tecnologia, curiosamente pouco problematizada na formação profissional de nível tecnológico, colabora para ofuscar tal função, seguindo a herança do discurso do progresso téc- 
nico positivista e dos primórdios do capitalismo industrial, com ênfase quase exclusiva na enunciação de seus aspectos benéficos intrínsecos e irrevogáveis.

Não se perde de vista aqui as próprias diretrizes da Educação Profissional e Tecnológica, segundo a Resolução CNE/CP no 3/2002 (BRASIL, 2002), que sustentam como um de seus pressupostos básicos para se alcançar essa formação tecnológica de qualidade, não permanecer encerrado apenas na instrução técnica que lhe é necessária, mas uma ampliação do escopo de sua formação, atendendo às demandas por problemas éticos, sociais e políticos implícitos ou explícitos que surgem em sua atuação profissional.

A formação profissional e tecnológica na atual tecnocultura, entrelaçada que está aos mecanismos do mercado, exige uma reconfiguração que vai além do simples ensino técnico e especializado para preenchimento de demandas de postos de trabalho a curto prazo. E não se trata de inferiorizar a formação tecnológica direcionada para o mercado, mas de problematiza-la, de repensar esse direcionamento, de olhar as mudanças, as permanências e os desafios que ela precisa enfrentar com urgência, para além dos muros econômicos e mercadológicos, tão importantes quanto insuficientes se o interesse é produzir uma EPT de qualidade estratégica, social e politicamente.

Ao colocar o mercado como aquele que regra os processos tecnológicos, estes são subsumidos muitas vezes ao fetiche da mercadoria tecnológica, juntamente com o trabalho dispendido pelos profissionais responsáveis pela manutenção e criação desses próprios processos e aparatos tecnológicos. O filósofo francês Gilbert Simondon (1969, 2005, 2008) diria que esta é uma maneira da cultura se defender da técnica. É fazer um uso utilitário da tecnologia, como simples encadeamentos de meios, desperdiçando sua potencialidade, algo típico do período pré-industrial ainda. Colocar cultura e tecnologia em oposição, para Simondon, seria um contrassenso, uma espécie de ressentimento da cultura em relação às técnicas, algo que não faz mais o menor sentido, ou pelo menos não deveria fazer após as transformações advindas da Teoria da Informação (SHANNON; WEAVER, 1949) e da Cibernética (WIENER 1968, 1970).
A escolha pelo uso do termo tecnocultura em vez de cibercultura ou mesmo cultura técnica, não é por comodidade ou algum tipo de modismo, mas por ser uma maneira já inicial de contestar essa separação entre tecnologia e cultura, de tentar conectar efetivamente essas duas palavras, de modo a compor uma noção que abranja e permita a reflexão a partir de outros espaços-tempos, que não restritos à Revolução Industrial ou à revolução a partir da chamada virada cibernética. Acoplar essas palavras é uma problemática de fundo que se reflete no modo como se concebe a tecnologia (não somente as contemporâneas) nas relações entre humanos e não humanos, a tecnologia como participante da cultura.

Percebe-se assim que não se trata apenas da inserção da tecnologia enquanto produto acabado na vida das pessoas, via consumo gerenciado pelo mercado, e da preparação de mão de obra qualificada para lidar com estas tecnologias. O como ela é criada, como é gestada, como ela é ensinada, como modifica as relações interpessoais e sociopolíticas é o que está em jogo. Como para além das oportunidades de trabalho, a própria concepção de trabalho e de classe trabalhadora são modificadas. Variáveis tecnossociais, de nível micro e macro, fazem parte da resolução de problemas já no embrião de uma tecnologia em sua interface com o trabalho e o mundo do trabalho.

Por isso, uma das trilhas fundamentais de investigações propostas nesse texto é a inclusão de uma discussão mais verticalizada referente à tecnologia ela mesma, aos seus conceitos, desdobramentos e tendências, uma vez que ela se restringe habitualmente a um ponto de vista utilitário, como foi dito. Parte-se de uma tecnologia pronta, como um produto acabado, limita-se a juízos de valor sobre seu uso e não se busca compreendê-la em seus aspectos históricos, políticos e tecnossociais, o que traz implicações formativas para aqueles, técnicos e tecnólogos, que, por definição, serão os responsáveis por inventa-las e gesta-las. É como se a técnica e a tecnologia, palavras que aliás estão em boa parte dos nomes dos cursos de EPT, fossem uma variável externa, um componente exógeno à discussão sobre as práticas educacionais, circunscritas apenas à lógica econômica por meio de outras duas palavras hoje mais utilizadas, 
inovação e empreendedorismo. A questão técnica e tecnológica estaria encerrada e diminuída nesse movimento, cuja lógica do mercado, que a bem da verdade nada entende de tal questão, mas sim de como gerar valor a partir dela (FREIRE, 2012), seria suficiente para guia-las da maneira mais satisfatória, o que no fundo ajuda a, no mínimo, limitar seu potencial.

A implicação de todo esse processo, em que o econômico toma as rédeas definitivamente, como legitimador único e último das ações tecnossociais, já fora diagnosticado no final dos anos 1970 por Lyotard (1998), ao descrever a condição pós-moderna, como ele a classificara. O imperativo da produtividade (para o mercado sempre), como já previa Marx (1978), quando falava da subsunção real do trabalho ao capital em seu conhecido Capítulo VI - Inédito, traduziu-se na lógica da performance e da formação por competências:

[...] as universidades e as instituições de ensino superior são de agora em diante solicitadas a formar competências e não mais ideias; tantos médicos, tantos professores de tal ou qual disciplina, tantos engenheiros, administradores, etc. A transmissão dos saberes não aparece mais como destinada a formar uma elite capaz de guiar a nação em sua emancipação. Ela fornece ao sistema os jogadores capazes de assegurar convenientemente seu papel junto aos postos pragmáticos de que necessitam as instituições. (LYOTARD, 1998, p. 88).

A expansão da sociedade industrial implicou na chamada universalização da escola, esta como agente social privilegiado para atender às requisições para o trabalho advindas do complexo industrial em constante desenvolvimento. Há uma sutil passagem aí, de uma formação centrada na necessidade comunitária em pequena escala para outra, em larga escala, a da indústria, cuja aceleração acontecia de maneira progressiva e se tornara exponencial com o advento da informática, gerando uma vertigem jamais vista, aceleração da aceleração, traduzida no imperativo da inovação tecnológica como motor para ampliação da capilaridade agora não mais somente fabril, mas empresarial em níveis globais. Uma nuance de nomenclatura nada inocente, pois impactante nas relações capital-trabalho e na concepção do papel da comunidade escolar nesse contexto.
Na passagem da fábrica para a empresa, na qual uma série de reconfigurações se desenharam nos últimos anos, Deleuze (1992, p. 223-224) observara que não se tratava apenas de uma evolução tecnológica, sem que fosse, mais profundamente, uma mutação do próprio capitalismo:

É uma mutação já bem conhecida que pode ser resumida assim: o capitalismo do século XIX é de concentração, para a produção, e de propriedade. Por conseguinte, erige a fábrica como meio de confinamento, o capitalista sendo o proprietário dos meios de produção, mas também eventualmente proprietário de outros espaços concebidos por analogia (a casa familiar do operário, a escola). Quanto ao mercado, é conquistado ora por especialização, ora por colonização, ora por redução dos custos de produção. Mas atualmente o capitalismo não é mais dirigido para a produção, relegada à periferia do Terceiro Mundo [...]. É um capitalismo de sobre-produção. Não compra mais matéria-prima e já não vende produtos acabados: compra produtos acabados, ou monta peças destacadas. O que ele quer vender são serviços, e o que quer comprar são ações. Já não é um capitalismo dirigido para a produção, mas para o produto, isto é, para a venda ou para o mercado. Por isso ele é essencialmente dispersivo, e a fábrica cedeu lugar à empresa.

Manter a longa citação foi necessário para se entender a lógica dessa mutação e como ela afeta decisivamente a triangulação entre formação profissional e tecnológica, mercado e cultura imbricada por tecnologias da informação. Há uma lógica que atravessa as ideias de educação a partir de um determinismo tecnológico, de trabalho restrito à produção econômica e produção como inovação.

Se os ciclos de vida dos produtos se reduziram, os capitais não têm outra opção para sobreviverem senão apostar em "inovar", ou correrem o risco de serem ultrapassados por empresas concorrentes, o que transforma a morfologia do trabalho e a relação com o consumo. Vale salientar que se trata de uma lógica de concorrência que justifica e encaixa-se perfeitamente à noção de formação por competências, ampliando a performance e a produtividade, mas não sem deixar suas contradições aparecerem. Por exemplo, Antunes (2005, p. 42, grifo do autor) aponta certa falácia, ou mesmo um ilogismo na lógica da produção supérflua e destrutiva da chamada 
"qualidade total": "quanto mais 'qualidade total' os produtos alegam ter, menor é seu tempo de duração", uma vez que é preciso aumentar a velocidade do ciclo reprodutivo do capital, diminuindo assim o tempo de vida útil dos produtos. Portanto, sugere-se ao mesmo tempo "qualidade total" com pouca durabilidade ou obsolescência rápida dos produtos, "inviabilizando práticas produtivas orientadas para as reais necessidades humano-sociais" (ANTUNES, 2005, p. 44). À educação só restar se alinhar a esta lógica, sendo o fracasso do desenvolvimento econômico atribuído ao fracasso da educação em "fornecer as destrezas relevantes" aos educandos (BERNSTEIN, 1996, p. 214).

Esse imbróglio ou impasse parece ainda não ter sido resolvido, ou se o foi, pendeu quase que exclusivamente para o mercado, numa relação unilateral, cuja seta acaba sempre seguindo um único sentido, do sistema produtivo para a educação, apesar da aparência de sentido múltiplo contida nas teorizações econômico-administrativas sobre a relação universidade-empresa para melhoria das condições socioculturais.

Assim, às categorias que se mostram universais e a-históricas como a própria noção de inovação, competência e mercado de trabalho, à posição humanista e subjetivista, parece necessário contrapor a recusa dos universais, a reflexão sobre a tecnocultura e a análise tecnológica dos mecanismos de poder que produzem subjetividades e as captura (FOUCAULT, 2010).

\section{Formação para o trabalho e os sujeitos trabalhadores}

Segundo Castioni (2010), o debate em torno dos temas educação, qualificação profissional e competência irrompeu no século XXI, transformando-se em assunto prioritário nas discussões que envolvem o tema do trabalho, tendo sempre a educação como elemento estruturante deste debate, das ações políticas que se convertem em políticas de governo e políticas de Estado. Não cabe nos limites deste estudo fazer a análise destas ações em seu conjunto ou mesmo de maneira específica, mas de pontuar como as noções de empregabilidade, competência e qualificação profissional em todos os níveis precisam ter como ponto de partida o debate em torno do conceito de trabalho para o qual as reformas educacionais se dirigem.

Nesta mesma direção aponta Maar (2006, p. 26) quando afirma que

O tema da centralidade do trabalho precisa ser focalizado tendo em vista o processo de produção e reprodução material da vida humana em sociedade, em sua interação com os outros homens e com a natureza. Neste processo os homens produzem a si próprios, a sociedade e as próprias formas sociais em que produzem.

A mutação do capitalismo, que tem o seu lócus principal não mais na fábrica, mas na empresa, obriga também uma reconfiguração da classe trabalhadora.

Se os parâmetros do que se entende como produção estão modificados, da mesma forma é necessário ampliar o conceito marxista de classe trabalhadora tradicionalmente abarcada pelos trabalhadores produtivos, ou seja, aqueles que vivendo da sua força de trabalho são assalariados. Assim, considera Antunes (2005) que todo trabalhador produtivo é assalariado e nem todo trabalhador assalariado é produtivo. Problematizar o conceito de trabalhador produtivo significa "incorporar a totalidade do trabalhador produtivo, do trabalho social coletivo, criador de valores de troca, do proletariado industrial moderno no conjunto da classe que vive do trabalho" (ANTUNES, 2005, p. 25).

Um conceito ampliado de classe trabalhadora nas atuais condições objetivas significa reconsiderar o conceito de trabalhador produtivo e incorporar, de alguma forma, também como parte dele os trabalhadores improdutivos, cujas formas de trabalho que são utilizadas como serviços também se constituem enquanto elementos vivos do processo de valorização do capital e de criação de mais-valia, por isso sendo necessários para a sobrevivência do sistema. Assim, Antunes (2005) considera parte dessa classe trabalhadora não só o proletariado industrial, mas os assalariados do setor de serviços, o proletariado rural, os trabalhadores terceirizados, os trabalhadores desempregados, sem deixar de ter destaque nesse cenário o trabalho das mulheres, dos negros, dos imigrantes e dos mais jovens, historicamente mais desvalorizados e precarizados. 
Contudo, para Antunes (2005), nessa visão ampliada de classe trabalhadora se excluem os gestores do capital, os altos funcionários que recebem rendimentos elevados por serem detentores do controle no processo de trabalho, de valorização e reprodução do capital. Antunes (2005) também reconhece que no processo de precarização do trabalho e de ampliação da classe trabalhadora impera um subjetivismo, um individualismo exacerbado em oposição às formas de solidariedade e de atuação coletiva e social. Esse subjetivismo encontra-se de maneira muito pontual na formação e na atuação dos altos executivos e se reflete na educação diretamente, inclusive na EPT, pois impera muitas vezes como modelo para os jovens em formação.

Como analisou Lopez-Ruiz (2007), os trabalhadores em geral têm nos altos executivos das transnacionais um paradigma a ser seguido à medida que incorporam o ideal da empresa como deles próprios, algo intrínseco às discussões atuais em torno do empreendedorismo, do intraempreendedorismo e da teoria do capital humano. Para Lopez-Ruiz (2007), esse paradigma sedutor revela-se numa lógica de seleção e concorrência em que o executivo transforma-se em misto de capital e trabalho, o trabalhador humano configurando-se como capital, alinhavando o sentido corrente do investimento em si mesmo, da formação permanente de habilidades, capacidades e destrezas, as competências como fonte de acumulação, na ideia de investimento-crescimento, do trabalhador-empresa.

Ao mesmo tempo que é importante refletir sobre a inserção ou não dos altos executivos dentro da categoria "classe trabalhadora", é importante considerar que os valores de formação e atuação profissional estão intimamente ligados à maneira como estes empregados altamente qualificados se inserem nas empresas. Se todo trabalho implica numa ideologia que o justifica, ser polivalente, multifuncional, investidor e empresário de si mesmo é o exemplo de trabalhador a ser seguido, numa trajetória em que a carreira profissional limita-se às competências e habilidades desenvolvidas por conta e risco do indivíduo que, por isso mesmo, torna-se o único responsável pelo fracasso profissional que o ronda permanentemente.

Se esse subjetivismo busca apreender a totalidade social de maneira fragmentada e individualista, minando a própria ideia de classe trabalhadora, é importante levar a sério esta configuração socialmente construída e discuti-la a partir de si mesma, ou seja, da sua ênfase no indivíduo e tudo que disso decorre, como a lógica das competências e a ênfase na ética. Essa ênfase na individualidade tem resultado no que pôde vislumbrar Max Weber (1982) como uma dominação crescente da burocracia no cotidiano dos sujeitos em suas diferentes ocupações e profissões.

Essa captura dos sujeitos pela burocracia (WEBER, 1982, 2004) e pelas instituições numa espécie de novo panoptismo (DELEUZE, 1992; FOUCAULT, 2010), Alves (2010, p. 45-46, grifo do autor) entende o mundo do trabalho como "escolha moral":

Na medida em que a 'captura' da subjetividade do homem que trabalha implica em escolhas pessoais, ela possui um denso lastro moral. [...] É o que denominamos de 'capitalismo Você S/A'. Por isso, o apelo às ideologias do empreendedorismo e trabalho por conta própria que usam e abusam da noção de 'talentos humanos' ou mesmo de 'capital humano'. (ALVES, 2010, p. 45-46).

Se Foucault (1987) esquadrinhara em Vigiar e Punir como ressoava o funcionamento das relações do poder do sistema industrial nas sociedades disciplinares, tratar conceitos de empreendedorismo e capital humano como recursos ideológicos hoje não os desqualificam como objeto de estudo e ponto de partida para uma reflexão sobre as condições objetivas do trabalhador numa dinâmica em que a fábrica dá lugar à empresa da era informacional como parâmetro e que alastra-se pelos diversos setores da sociedade, incluindo a EPT. A humanização do processo econômico - aquele que diz onde, como e quando investir - pode ser vista num simples logo-conceito de uma revista, unindo termos em princípio paradoxais, como Você e S/A, dando um indício do alcance da modificação da noção de classe trabalhadora e de suas lutas possíveis. Afinal, como resistir ou fazer reinvindicações trabalhistas, por exemplo, contra si mesmo, se você é, ou se sente, como a própria corporação?

Há um trecho no livro de Lopez-Ruiz (2007) em que ele relata uma de suas entrevistas realizadas com a diretora de redação dessa revista, a VOCÊ S/A: "Quando perguntamos sobre o nome da revista, o que designava esse nome, a resposta foi clara 
e contundente: 'O 'VOCÊ' é o você indivíduo, o 's.a' é a corporação que você tem que administrar, que é a sua carreira' (LÓPEZ-RUIZ, 2007, p. 255).

Depois o autor conta que o 's.a' em minúsculo passou para maiúsculo ' $\mathrm{S} / \mathrm{A}$ ', e sua entrevistada diz o porquê: "O estudo da agência dizia que com aquele nome estava sendo dada maior importância para o 'você' do que para o 's.a.', dando a impressão de que o indivíduo é mais importante que a sua própria carreira ou a maneira como ele está inserido no mercado de trabalho". (LÓPEZ-RUIZ, 2007, p. 256).

Ou seja, há a necessidade de estudos para entender melhor esse contexto em que o gasto em si é visto como investimento para o futuro e que, portanto, o consumo torna-se investimento. Mais ainda, como essa ideologia se reflete no cotidiano da formação educacional, na aquisição permanente de habilidades, destrezas e competências específicas e especializadas para aumento de performance atual e a criação de uma espécie de poupança, de uma acumulação de responsabilidade individual para sobrevivência futura, onde o emprego não é mais garantindo, pois "você é o seu projeto" (LOPEZ-RUIZ, 2007, p. 254).

Buscar o conteúdo de verdade da ideologia significa procurar entender a motivação que leva os indivíduos a aderir a seus pressupostos e confrontar os conceitos com sua realidade concreta. Entender também a que propósito, o que e quais são os pensamentos dominantes:

Os pensamentos dominantes nada mais são do que a expressão ideal das relações materiais dominantes; eles são essas relações materiais dominantes consideradas sob forma de ideias, portanto a expressão das relações que fazem uma classe a classe dominante; em outras palavras, são ideias de dominação (MARX; ENGELS, 1998, p. 48).

Nessa direção, na busca de fundamentação nos estudos de EPT, consideramos necessários os estudos empíricos sobre as condições de trabalho num sentido coletivo e estrutural, mas também o enfrentamento dessas individualidades capturadas a partir de uma discussão sobre o cotidiano do trabalho nas mais diversas esferas da produção, resgatando e reconstruindo conceitos, e não simplesmente tomando-os como verdades a-históricas e genéricas.
Como pôde considerar Marx (1989, p. 78), “o apelo para que abandonem as ilusões a respeito de suas condições é o apelo para abandonarem uma condição que precisa de ilusões". Entretanto é importante refletir por que as ilusões tornam-se necessárias e por isso possuem o seu conteúdo de legitimação e objetividade. Ou seja, não se trata de opor ideologia à verdade ou à realidade pura e simplesmente. Mesmo porque ideologia e realidade, como considerou Adorno (1973, p. 203), se convertem numa só coisa:

[...] o homem adapta-se às condições dadas em nome do realismo. Os indivíduos sentem-se, desde o começo, peças de um jogo e ficam tranquilos. Mas, como a ideologia já não garante coisa alguma, salvo que as coisas são o que são, até a sua inverdade específica se reduz ao pobre axioma de que não poderiam ser diferentes do que são. Os homens adaptam-se a essa mentira, mas, ao mesmo tempo, enxergam através do seu manto. A celebração do poder e a irresistibilidade do mero existir são as condições que levam ao desencanto. A ideologia já não é mais um envoltório, mas a própria imagem ameaçadora do mundo. Não só pelas suas interligações com a propaganda, mas também pela sua própria configuração, converte-se em terror. Entretanto, precisamente porque a ideologia e a realidade correm uma para outra; porque a realidade dada, à falta de outra ideologia mais convincente, converte-se em ideologia de si mesma, bastaria ao espírito um pequeno esforço para se livrar do manto dessa aparência onipotente, quase sem sacrifício algum. Mas esse esforço parece ser o mais custoso de todos.

Para Maar (2006, p. 26), a centralidade do trabalho diz respeito à crítica às formas sociais determinadas na formação vigente, ou seja:

[...] ao economicismo que instrumentaliza as relações sociais em termos de produtividade capitalista; à mercantilização generalizada, que subordina a vida social ao consumismo e aos ditames da indústria cultural; à destruição ambiental resultante de uma relação com a natureza objetivada em matéria de exploração predatória; à política instrumental que subordina a ampliação dos direitos sociais à mera circulação no acesso aos mecanismos de poder etc.

Não se pode promover, portanto, a EPT sem discutir ampla e incansavelmente as relações entre educação e trabalho, entre desenvolvimento tecnocientífico e tecnocultura. Trabalho abstrato, traba- 
lho doméstico, divisão do trabalho, trabalho e força de trabalho e a natureza do trabalho, trabalho e mais valia, trabalho produtivo e improdutivo, questões de gênero no mercado de trabalho são conceitos a serem estudados, discutidos e problematizados para além das práticas de ensino e extensão voltadas estritamente para o mercado.

\section{Considerações finais}

Desde o início de sua implementação, nos anos de 1990, o mestrado profissional tem sido considerado uma modalidade de pós-graduação que precisa ter maior ênfase na profissionalização e gestão das mais diversas formas de atividades sociais, empresariais, tecnológicas e culturais. Isso num contexto de aperfeiçoamento profissional, já que o mercado de trabalho tem exigido sujeitos trabalhadores que consigam solucionar problemas do cotidiano a partir de uma formação teórico-prática, ao mesmo tempo contemplando as dimensões estratégicas e operacionais.

O desafio que se apresenta, com o processo de expansão das redes privadas e públicas de EPT, também é o da formação ampla de quadros pós-graduados, dada a relevância que essa modalidade de ensino tem alcançado nas últimas décadas e os esforços ainda muito iniciais para a formação para a docência, para a gestão e para a pesquisa neste segmento. Ou seja, trata-se, sim, de, por meio do mestrado profissional, também formar docentes e pesquisadores para a EPT, algo que não se apresentava como uma questão a ser debatida nos anos de 1990.

É fundamental que as leituras específicas sobre a EPT, em seus mais diversos aspectos correlacionados, permitindo uma visualização mais abrangente do conceito e da constituição do ensino tecnológico ao longo do tempo, e mais especificamente no Brasil, estejam articuladas à compreensão histórico-social do conceito de trabalho e o papel central que tem assumido ao longo dos projetos educacionais e na própria experiência laboral dos trabalhadores frente às mudanças nas relações de produção.

Se é com o desenvolvimento das relações sociais produtivas capitalistas que a categoria "trabalho" assume o sentido de emprego remunerado e "trabalhador" para designar a classe trabalhadora (FRIGOTTO, 2009), se essa classe trabalhadora se vê regulada pelo tipo ideal do alto executivo mesmo sem sê-lo (LOPEZ-RUIZ, 2007) e se há a captura das subjetividades dos trabalhadores no processo de reestruturação produtiva (ALVES, 2010), à categoria "trabalho" nos estudos sobre formação profissional e para a formação profissional deve-se confrontar sempre o conceito de trabalho à realidade concreta vivida pelos sujeitos, realidade esta interpretada por meio das noções pouco problematizadas de "competência", "empregabilidade", “inovação", "capital humano”, "empreendedorismo", entre outras.

É importante que nos estudos sobre a categoria "trabalho" num espaço permanente de formação profissional, todas estas noções sejam confrontadas com os dados concretos do trabalho e dos trabalhadores, especialmente para os jovens que chegam à EPT mediante a promessa de maiores facilidades para a inserção no mercado de trabalho por meio de uma formação técnica e tecnológica.

Portanto, este artigo apresenta nos estudos sobre os fundamentos da EPT a necessidade de se enfatizar a categoria "trabalho" na formação, buscando além dos conceitos e de uma abordagem epistemológica, o contraponto destes conceitos e ideias reguladoras frente à realidade concreta dos sujeitos trabalhadores. Defende-se a leitura e problematização de tais conceitos à luz de uma abordagem sócio-histórica e filosófica em contraponto à perspectiva neoliberal, que tem se legitimado pelo desempenho, pelas noções de empregabilidade e de competência.

Isso significa não colocar em segundo plano os estudos de caráter humanístico e histórico, sem o que permaneceremos indefinidamente na dualidade estrutural que marca a educação profissional no Brasil. Dualidade estrutural no sentido epistemológico, que separa e hierarquiza formação acadêmica e profissional, e a dualidade social e econômica, com consequências políticas importantes.

A EPT não pode deixar de articular a ciência, a tecnologia, a cultura e o trabalho como eixos estruturantes da sua historicidade e das suas perspectivas, o que implica numa problematização não só dos cursos técnicos e tecnológicos ofertados, mas de uma discussão ampla nos programas de pós-graduação, visando à formação de seus professores, gestores e pesquisadores. 


\section{REFERÊNCIAS}

ABRAMO, H. W.; BRANCO, P. P. M. (Org.). Retratos da juventude brasileira: análises de uma pesquisa nacional. São Paulo: Fundação Perseu Abramo, 2005.

ABRAMO, H. W. et al. Agenda Juventude Brasil. Brasília, DF: Secretaria Nacional de Juventude, 2014. Disponível em: $<$ https://issuu.com/participatorio/docs/agenda_juventude_brasil_-_pesquisa_/1?e=12152407/10902032>. Acesso em: 20 fev. 2015.

ADORNO, T. W. Ideologia. In: ADORNO, T. W.; HORKHEIMER, M. Temas básicos da sociologia. São Paulo: Cultrix, 1973. p. 184-203.

ALCÂNTARA, A. B.; COSTA, R. M. A. In: CONGRESSO BRASILEIRO DE HISTÓRIA DA EDUCAÇÃO, 8. 2014, Maringá. Anais... Maringá, PR: ANPOLL, 2014. Novo Plano. Novos desafios. Eixo Temático: 1 - Estado e Políticas Educacionais na História da Educação Brasileira.

ALVES, G. Trabalho, capitalismo global e “captura” da subjetividade: uma perspectiva crítica. In: SANT'ANA, R. S. et al. (Org.). O avesso do trabalho II: trabalho, precarização e saúde do trabalhador. São Paulo: Expressão Popular, 2010.

ANTUNES, R. O caracol e sua concha: ensaios sobre a nova morfologia do trabalho. São Paulo: Boitempo, 2005.

BATISTA, S. S. S.; FREIRE, E. (Org.). Educação profissional e tecnológica: perspectivas e experiências. v. 1. Jundiaí, SP: Paco Editorial, 2015.

BERNSTEIN, B. A estruturação do discurso pedagógico: classes, códigos e controle. Petrópolis, RJ: Vozes, 1996.

BRASIL. Ministério da Educação. Conselho Nacional de Educação. Resolução CNE/CP n ${ }^{\mathbf{0}}$ 3, de 18 de dezembro de 2002. Disponível em: <http://portal.mec.gov.br/cne/arquivos/pdf/CP032002.pdf>. Acesso em: 20 jul. 2016

BRYAN, N. A. P. Educação, processo de trabalho e desenvolvimento econômico. Campinas, SP: Alínea, 2008.

CASTIONI, R. Educação no mundo do trabalho: qualificação e competência. São Paulo: Francis, 2010.

CIAVATTA, M.; RAMOS, M. A “era das diretrizes": a disputa pelo projeto de educação dos mais pobres. Revista Brasileira de Educação, Rio de Janeiro, v. 17, n. 49, jan.-abr. 2012.

COORDENAÇÃO DE APERFEIÇOAMENTO DE PESSOAL DE NÍVEL SUPERIOR (Capes). INFOCAPES Boletim Informativo do Capes, Brasília, DF, v. 7, n. 3, 1999. Disponível em: <https://www.capes.gov.br/images/ stories/download/bolsas/Info3_99.pdf>. Acesso em: 03 jul. 2016.

DELEUZE, G. Post-scriptum sobre as sociedades de controle. In: 34, 1992. p. 219-226.

Conversações. Rio de Janeiro: Editora

FOUCAULT, M. Do governo dos vivos. Rio de Janeiro: Achiamé, 2010.

Vigiar e punir. Petrópolis, RJ: Vozes, 1987.

FREIRE, E. Tecnólogo e o mercado: uma relação a ser revisitada. In: ALMEIDA, I. B.; BATISTA, S. S. dos S. (Org.). Educação tecnológica: reflexões, teorias e práticas. São Paulo: Paco, 2012. p. 103-116.

FRIGOTTO, G. A polissemia da categoria trabalho e a batalha das ideias nas sociedades de -classe. Revista Brasileira de Educação, Rio de Janeiro, v. 14, n. 40, p. 168-194, jan./abr. 2009.

INSTITUTO BRASILEIRO DE GEOGRAFIA E ESTATÍSTICA (IBGE). Pesquisa Nacional por Amostra de Domicílios (PNAD). Síntese dos indicadores. Disponível em: <http://biblioteca.ibge.gov.br/visualizacao/livros/ liv45767.pdf>. Acesso em: 20 mar. 2015.

LEITÃO, A. Desafio da implementação das políticas na gestão estadual. In: LOBATO, A. L. (Org.). Jovens mulheres e políticas públicas. Brasília, DF: Ministério da Justiça e Cidadania/Secretaria Nacional de Justiça, 2014. (Série Juventude Estudos). p. 66-76.

LÓPEZ-RUIZ, O. J. Os executivos das transnacionais e o espírito do capitalismo. Capital humano e o empreendedorismo como valores sociais. Rio de Janeiro: Azougue, 2007.

LYOTARD, J-F. A condição pós-moderna. Rio de Janeiro: José Olympio, 1998. 
MAAR, W. L. A dialética da centralidade do trabalho. Revista Ciência e Cultura, São Paulo, v. 58, n. 4, out./dez. 2006.

MACHADO, L. R. de S. O profissional tecnólogo e sua formação. Revista da Rede de Estudos do Trabalho (RET), ano II, n. 3, p. 1-28, 2008. Disponível em: <http://www.estudosdotrabalho.org/LuciliaMachado.pdf $>$. Acesso em: 20 jul. 2016.

Organização da educação profissional e tecnológica por eixos tecnológicos. Revista Linhas Críticas, Brasília, DF, v. 16, n. 30, p. 89-108, 2010.

MANFREDI, S. M. Educação profissional no Brasil. São Paulo: Cortez, 2002.

MARQUES, L. A construção de uma agenda das jovens mulheres e o mundo do trabalho. In: LOBATO, A. L. (Org.). Jovens mulheres e políticas públicas. Brasília, DF: Ministério da Justiça e Cidadania/Secretaria Nacional de Justiça, 2014. (Série Juventude Estudos). p. 142-151.

MARX, Karl. O capital - Livro I Capítulo VI (Inédito). São Paulo: Livraria Editora Ciências Humanas, $1^{\text {a }}$. Edição, 1978.

Manuscritos econômico-filosóficos. Lisboa: Edições 70, 1989.

MARX, K.; ENGELS, F. A ideologia alemã. São Paulo: Martins Fontes, 1998.

QUELHAS, O. L. G.; FARIA FILHO, J. R.; FRANÇA, S. L. B. O mestrado profissional no contexto do sistema de pós-graduação brasileiro. Revista Brasileira de Pós-graduação, v. 2, n. 4, p. 97-104, jul. 2005.

SHANNON, C. E.; WEAVER, W. The mathematical theory of communication. Chicago: University of Illinois Press, 1949.

SILVA, M. R. da; PELISSARI, L. B.; STEIMBACH, A. A. Juventude, escola e trabalho: permanência e abandono na educação profissional técnica de nível médio. Revista Educação e Pesquisa, São Paulo, v. 39, n. 2, p. 403-417, abr./jun. 2013.

SILVEIRA, V. O. da; SOUZA PINTO, F. C. Reflexões necessárias sobre o mestrado profissional. Revista Brasileira de Pós-graduação, v. 2, n. 4, p. 38-47, jul. 2005.

SIMONDON, G. Du Mode d'existence des objets techniques. Paris: Aubier-Montaigne, 1969.

Imagination et invention. Chatou: Les Éditions de La Transparence, 2008.

2005.

. L'individuation à la lumière des notions de forme et d'information. Grenoble: Éditions Jérome Millon,

SNJ - Secretaria Nacional de Juventude. Agenda juventude Brasil: pesquisa nacional sobre o perfil e opinião dos jovens brasileiros. Brasília: SNJ, 2014.

WEBER, M. A ética protestante e o espírito do capitalismo. São Paulo: Companhia das Letras, 2004.

Ensaios de sociologia. Rio de Janeiro: Zahar, 1982.

WIENER, N. Cibernética e sociedade: o uso humano de seres humanos. São Paulo: Cultrix, 1968.

. Cibernética, ou controle e comunicação no animal e na máquina. São Paulo: Polígono, 1970.

Recebido em: 20/07/2016

Aprovado em: 14/09/2016 